\title{
FORÇA E FRAGILIDADE DO SISTEMA DE INOVAÇÃO PAULISTA
}

\author{
RuY Quadros \\ Professor do Departamento de Política Cientifica e Tecnológica da Unicamp, Consultor da Fundação Seade \\ SANDRa BRISOLLA \\ Professora do Departamento de Política Científica e Tecnológica da Unicamp, Consultora da Fundação Seade \\ André Furtado \\ Professor do Departamento de Política Científica e Tecnológica da Unicamp, Consultor da Fundação Seade \\ RoBerto BERnardes \\ Sociólogo, Analista da Fundação Seade
}

\begin{abstract}
Resumo: Este artigo tem como objetivo fazer um exercício de reflexão sobre o "sistema de inovação paulista" à luz da análise das informações sobre o sistema público de C\&T no Estado de São Paulo e abordar os principais problemas das universidades e dos institutos públicos de pesquisa, estaduais e federais. São discutidos os obstáculos de integração entre empresas e o setor público de C\&T, mapeando os fatores que determinam a baixa demanda do sistema produtivo paulista em relação ao sistema público de C\&T.

Palavras-chave: sistema de inovação; sistema de ciência e tecnologia paulista; política científica e tecnológica.
\end{abstract}

$\mathrm{O}$ conhecimento científico e o tecnológico, impulsionados pelos fluxos de investimentos em indústrias high-tech, em P\&D (Pesquisa e Desenvolvimento) e capital humano, vêm lapidando um novo significado ao conceito contemporâneo de produtividade, implicando em um padrão mais sistêmico e integrado, consolidando o conhecimento e a informação como dínamos motrizes do ciclo de desenvolvimento econômico e na formação de poder e da riqueza das empresas, regiões e nações. Essa nova perspectiva teórica tenta traduzir o significado da produção, distribuição e do uso do conhecimento e da informação - acelerados pelas novas tecnologias de informação e comunicação (TICs) - como elementos nucleares para a mudança social, progresso tecnológico e o desenvolvimento econômico das nações avançadas (OECD, 1996a).

A formulação de expressões como "economias baseadas em conhecimento" (Foray e Lundvall, 1996; Dosi, 1998), "sociedade da informação" (Bell, 1976; Castells, 1997), "economia do aprendizado" (Storper, 1996), "capitalismo de alianças, relacional e coletivo" (Dunning, 1997), tenta retratar, grosso modo, a transição de um modelo linear de inovação e C\&T (Ciência e Tecnologia) para um modelo de ligações em cadeia (chain linked model) (Kline e Rosenberg, 1986), e posteriormente, alterando-se para um padrão sistêmico (Archibugi e Sirilli, 2000), no qual a idiossincrasia, diversidade e seletivida- de dos ambientes e das instituições, e os sistemas e redes (networks) de conhecimentos locais, regionais ou transterritoriais adquirem efeitos sinergéticos e sistêmicos mutuamente reforçantes ou excludentes em relação às oportunidades tecnológicas e à inserção dos espaços locais diante do processo de globalização econômica (Campolina, 2000).

Johnson e Lundvall (2000:3), entretanto, advertem que uma economia baseada em conhecimento e aprendizado não é exclusivamente uma "high-tech economy", pois o aprendizado experimentado nas várias dimensões da economia, e a sua contribuição mesmo aqueles setores denominados "low-tech" ou tradicionais (vestuário, têxteis, calçados, etc.), revelam-se fatores críticos para o desenvolvimento econômico e tecnológico. Nessa visão, os mecanismos institucionais de aprendizado e interação (learning by interacting) são a chave do processo de mudança para a acumulação do conhecimento, da inovação, para a destruição e recriação das competências-chave direcionadas para o crescimento. As empresas encontram-se no epicentro das transformações tecnológicas dessa nova economia. Paradoxalmente, as decisões empresariais de investimentos em tecnologia e produção são comandadas cada vez mais por uma forte racionalidade de valorização dos ativos pelos circuitos dos mercados e instituições financeiras globais, impondo ao regime de acumulação um domínio financeiro da economia (Chesnais, 2000). 
Nesse quadro, a nova matriz teórica sobre as políticas de inovação e os sistemas de C\&T passa a ser fundamentada no advento de novos arranjos institucionais mais complexos e multilaterais direcionados para a inovação e o aprendizado tecnológico, revitalizando as relações entre universidade-indústria-governo e, por fim, na promoção de sistemas sustentáveis que criem competências dinâmicas para o surgimento da inovação (Leydesdorff e Etzkowitz, 1998; Johnson e Lundvall, 2000). Essas novas institucionalidades nas dinâmicas inovativas são interdependentes das trajetórias nacionais, da formação de mecanismos formais e informais que promovam a confiança e cooperação entre os agentes (Edquist, 1997), permitindo a transmissão do conhecimento tácito e codificado, na arquitetura de redes cooperativas transversais de conhecimento, e uma "atmosfera industrial inovativa" que estimule as rotinas de aprendizagem coletiva, do tipo produtor/usuário, fornecedor/produtor, reduzindo as incertezas, os riscos de investimentos e os custos de transação com o incremento da "eficiência coletiva dinâmica" ao longo das cadeias produtivas locais e globais (Humphrey e Schmitz, 1996; Gereffi e Korzeniewicz, 1995).

Os sistemas de ciência e tecnologia, constituem-se em uma parte dos sistemas de inovação, exercendo uma função vital nas economias baseadas em conhecimento, particularmente pela construção de elos virtuosos de cooperação entre as empresas, governo e universidades, adquirindo uma relevância crescente nas demandas sociais das mais diversas áreas como saúde, biotecnologia, educação, meio ambiente, meteorologia, agricultura, aeroespaciais e comunicação. Com efeito, os laboratórios de pesquisa pública e instituições de ensino educacional são o coração desse sistema, que inclui a infra-estrutura governamental, os conselhos de pesquisas, agências de fomento e as políticas públicas, potencializadas pela construção de núcleos de inovações endógenas nessas economias, amparados em robustos sistemas de inovação locais/subnacionais/nacionais (Freeman, 1998; Nelson, 1993; Lundvall 1992; Cassiolato e Lastres, 1999). O sistema de C\&T, por exemplo, pode contribuir nas seguintes dimensões (OECD, 1996a):

- produção do conhecimento - desenvolvendo o conhecimento básico;

- transmissão do conhecimento - educando e formando recursos humanos; e,
- transferência do conhecimento - disseminando o conhecimento e identificando inputs para demandas sociais e empresariais futuras. Vale salientar que os esforços de pesquisa básica e invenção são de atribuição das universidades e centros de pesquisa, já o processo de inovação passa a ter como locus privilegiado para a acumulação tecnológica os espaços produtivos das empresas.

Não obstante o Brasil apresente um padrão de desenvolvimento caracterizado por alguns entraves estruturais históricos, herdados do seu processo de industrialização, como uma estrutura produtiva marcada por profunda heterogeneidade, frágeis processos de aprendizado e uma capacidade limitada de inovação tecnológica (Coutinho e Ferraz, 1994; Quadros Carvalho, 1993), construiu em sua trajetória um sistema de C\&T importante, posicionandose em uma situação intermediária entre os países de industrialização recente, mas ainda prosseguindo bastante distante da condição de delinear trajetórias de catching up em relação às nações líderes (Villaschi, 1993; Albuquerque, 1996; Viotti, 1997).

Nesse quadro, o Estado de São Paulo destaca-se regionalmente respondendo por uma parcela expressiva dessa base tecnológica nacional constituída, seja pelo critério de dispêndios $(32,0 \%)$ ou de resultados $(50,0 \%)$. No entanto, uma das características mais frágeis dos sistemas de C\&T brasileiro e paulista é identificada na fraca integração entre o sistema público de $\mathrm{C} \& \mathrm{~T}$ e o sistema produtivo, que se reflete no contraste entre o crescimento da produção científica e a estagnação da produção tecnológica empresarial. Essa questão é o foco deste artigo e orientou sua organização em quatro seções, além desta introdução. Na primeira seção, é descrito e analisado o sistema público de C\&T no Estado de São Paulo; são abordados os principais problemas sobre as universidades e os institutos públicos de pesquisa, estaduais e federais, como de recursos humanos e orçamentários; a situação relativa no cenário brasileiro; e a crise de financiamento dos institutos de pesquisa. Na segunda seção, os problemas da integração entre empresas e o setor público de C\&T são tratados em maior profundidade e são discutidos os fatores determinantes da baixa demanda do sistema produtivo paulista em relação ao sistema público de C\&T. Além disso, são repassadas as principais iniciativas governamentais para promover a integração empresa/pesquisa pública. Na terceira seção, são analisadas a performance e a natureza da inovação e das atividades de P\&D nas empresas paulistas. Finalmen- 
te, a última seção resume os pontos principais do trabalho e aponta as principais conclusões.

\section{O SISTEMA PÚBLICO DE C\&T: AVALIAÇÃO E EVIDÊNCIAS EMPÍRICAS}

O Sistema Público de C\&T do Estado de São Paulo é o mais diversificado e desenvolvido dentre os sistemas estaduais do país. Resultado de investimentos estaduais e federais sistemáticos, ao longo de três décadas, esse Sistema revela sua excelência no fato de ser responsável por metade da produção científica brasileira. Além disso, contribui para o desenvolvimento científico e tecnológico de outros Estados, seja pela formação de cerca de dois terços de todos os doutores brasileiros, ou por de uma intensa cooperação em pesquisa com universidades, empresas e institutos desses Estados. A Secretaria de Ciência e Tecnologia e Desenvolvimento Econômico (SCTDE) é o órgão coordenador das instituições estaduais de pesquisa e das ações de apoio e promoção ao desenvolvimento tecnológico empresarial, tendo o Conselho Estadual de Ciência e Tecnologia (Concite) a missão institucional de formular a política tecnológica do Estado de São Paulo. Nesta seção, são caracterizados e discutidos, à luz dos principais indicadores brasileiros, os principais componentes do Sistema Público de C\&T paulista - as universidades públicas, os institutos de pesquisa e as agências de fomento -, bem como alguns de seus problemas atuais, especialmente aqueles referentes ao seu financiamento, que ameaçam a continuidade dos resultados acumulados.

\section{A Presença das Universidades Estaduais e Federais}

São Paulo é o único Estado do Brasil onde as universidades mais importantes não são federais, e sim estaduais.
Isso decorre da histórica importância econômica do Estado, que resultou em sua maior autonomia financeira. A primeira universidade estabelecida no país foi a Universidade de São Paulo, mantida com recursos do Tesouro estadual. O Estado de São Paulo mantém um sistema de pesquisa cujos principais componentes são os docentes das três universidades públicas. Esse sistema destaca-se dentro do cenário nacional de universidades públicas e privadas, conforme se observa na Tabela 1. É notável a diferença de titulação, visível pelo percentual de doutores nas universidades em São Paulo (de 59,0\% a 66,0\%), em relação à média de participação de doutores nas universidades públicas do país $(22,0 \%)$. As universidades privadas, além de ter pouco pessoal titulado, empregam boa parte de seu pessoal em meio período.

Somando cerca de 11 mil pesquisadores, esses docentes desempenham, no sistema de educação superior no país e no sistema de pesquisa nacional, um papel muito superior à sua representação percentual no total de docentes das instituições públicas de ensino superior brasileiras, uma vez que o Estado de São Paulo é responsável por metade da produção científica brasileira. Esses docentes representam quase três quartos dos pesquisadores no Estado.

O sistema universitário público paulista é financiado preponderantemente por recursos orçamentários. Essas despesas, em 1997, somaram R \$ 1,7 bilhão, representando 7,4\% da arrecadação de ICMS, ou $6,62 \%$ das receitas tributárias, ou ainda 5,27\% das receitas correntes do Estado. É esse compromisso com a educação, a ciência e a tecnologia - uma aposta no futuro - que tem mantido o Estado na vanguarda da produção econômica, social e cultural. Não apenas para a pesquisa e a docência voltamse as atividades das universidades públicas paulistas. Elas desempenham uma função social básica entre a população - principalmente mas não unicamente de renda mais baixa -, ao manter o pessoal e as instalações de vários

TABELA 1

Docentes das Universidades Públicas, por Nivel de Titulação Estado de São Paulo e Brasil - 1995

\begin{tabular}{|c|c|c|c|c|c|}
\hline Tipos de Universidade & Graduação/Especialização & Mestrado & Doutorado & Total & Doutorado/Total (\%) \\
\hline Universidades do Estado de São Paulo & 304 & 3.731 & 5.826 & 9.861 & 59,0 \\
\hline Universidades Federais em São Paulo & 76 & 348 & 827 & 1.251 & 66,0 \\
\hline Instituições Públicas de Ensino Superior no Brasil (1) & 37.005 & 21.268 & 16.850 & 75.123 & 22,0 \\
\hline Instituições Privadas de Ensino Superior no Brasil (1) & 49.350 & 12.263 & 4.476 & 66.089 & 7,0 \\
\hline
\end{tabular}

Fonte: SEEC/MEC e Fapesp.

(1) Inclui as universidades paulistas. 
hospitais-escola, onde o atendimento é de padrão internacional, ainda que insuficiente para atender a uma demanda intensa. Assim mesmo, deve-se reconhecer o papel social que esses hospitais desempenham no sistema de saúde do país. A qualidade dos hospitais vinculados às universidades públicas paulistas é reconhecida e, em algumas áreas, a pesquisa médica situa-se na fronteira do conhecimento. Esse é sem dúvida o caso da pesquisa realizada no Instituto do Coração (Incor) e também na Faculdade de Medicina da USP, da Santa Casa e da Unicamp, para citar as mais importantes. O Brasil lidera incontestavelmente a formação de doutores na área de ciências médicas na América Latina.

Depois de duas décadas de estagnação econômica, é evidência de resistência e determinação que o sistema público de pesquisa e pós-graduação, cuidadosamente construído nas universidades públicas paulistas, sobreviva com boa capacidade produtiva, apesar de já dar demonstração de problemas estruturais que podem comprometer o estágio alcançado. Dependente de recursos públicos para a manutenção de suas atividades, o que também ocorre com o sistema universitário de boa qualidade - público ou privado - nos Estados Unidos e na Europa, as universidades paulistas enfrentam os problemas comuns às instituições que vivem de recursos do Estado brasileiro na atualidade: dificuldades crescentes de acesso a financiamento e falta de condições (infra-estrutura) adequadas de trabalho. Particularmente sério é o estrangulamento de recursos orçamentários decorrente do pagamento de aposentadorias nas universidades, em virtude do crescimento rápido do número de docentes aposentados, num quadro financeiro em que os recursos orçamentários das universidades têm de financiar compulsoriamente os benefícios previdenciários. Se persistirem os motivos que causam essa crescente dificuldade, há risco de colapso para o excelente sistema de pesquisa e pós-graduação construído a duras penas pelo consórcio efetivo que se realizou entre o governo federal (pela ação da Capes e do CNPq) e o governo estadual (pela manutenção da verba orçamentária das universidades e da Fundação de Amparo à Pesquisa - Fapesp), durante os últimos 30 anos (USP, 2000).

\section{Institutos Públicos de Pesquisa: elo crítico entre o sistema produtivo e a sociedade}

Os institutos de pesquisa têm uma função muito importante no sistema científico e tecnológico que está sob a responsabilidade do setor público. São instituições orien- tadas para a pesquisa aplicada e o desenvolvimento tecnológico, que atendem a demandas mais orientadas da sociedade e do sistema produtivo. Boa parte desses institutos tem uma nítida vocação setorial e possui objetivos claramente direcionados para o desenvolvimento de tecnologias. Sua clientela é formada pelas empresas e por certas demandas específicas da sociedade (saúde, alimentação, infra-estrutura, telecomunicações, meteorologia). Eles podem ser considerados, na maioria dos casos, um elo entre a pesquisa acadêmica, que está localizada principalmente nas universidades, e o sistema socioprodutivo.

O Estado de São Paulo conta com uma importante rede de institutos de pesquisa. Dentro do setor público, eles ocupam um lugar de destaque logo após as universidades. Os institutos de pesquisa costumam ser financiados por recursos orçamentários, embora estes recursos estejam perdendo espaço progressivamente em benefício de outras fontes do setor público e do setor privado. A origem dos recursos orçamentários define duas modalidades principais de institutos públicos de pesquisa no Estado: os institutos federais e os institutos estaduais. Contrariamente à situação das universidades, os institutos federais são mais importantes do que os institutos estaduais em termos de recursos gastos, embora estes últimos utilizem um maior contingente de pesquisadores (Tabela 2).

Os institutos públicos federais ocupam um lugar de destaque no cenário paulista e formam uma das principais áreas de alocação de recursos federais aplicados em C\&T no Estado de São Paulo. Com efeito, segundo o levantamento feito pela Fapesp para o ano de 1995, os institutos federais são responsáveis por $51,63 \%$ dos recursos da União destinados à C\&T no Estado de São Paulo. Esse número revela a importância desses institutos no contexto estadual e também nacional. Os institutos federais localizados no Estado de São Paulo respondem por 32\% do gasto da União com essa modalidade de institutos no país.

TABELA 2

Gastos e Recursos Humanos de Nível Superior Alocados a Institutos Públicos de Pesquisa Estado de São Paulo - 1995

\begin{tabular}{lcc}
\hline $\begin{array}{l}\text { Institutos Públicos } \\
\text { de Pesquisa }\end{array}$ & $\begin{array}{c}\text { Gastos } \\
\text { (Em US\$ milhões de 1995) }\end{array}$ & $\begin{array}{c}\text { Engenheiros e } \\
\text { Cientistas }\end{array}$ \\
\hline Total & $\mathbf{5 3 7 , 4 2}$ & 3.605 \\
Institutos Federais (1) & 338,40 & 1.262 \\
Institutos Estaduais & 199,02 & 2.343 \\
\hline
\end{tabular}

Fonte: Fapesp.

(1) Exclui o Centro de Pesquisa e Desenvolvimento - CPqD. 
A maior parte dos institutos de pesquisa federais localizados no Estado de São Paulo se destina às áreas estratégicas. São eles, principalmente, o Centro Tecnológico da Aeronáutica (CTA), o Instituto de Pesquisas Espaciais (Inpe) e o Instituto de Pesquisas Nucleares (Ipen), muito sensíveis às prioridades das políticas governamentais e aos imperativos das políticas macroeconômicas. O setor aeroespacial ocupa um lugar de destaque entre essas áreas estratégicas e tem sido impulsionado pelo Programa Espacial Brasileiro, sob a condução da Agência Espacial Brasileira, que ultimamente sofreu importantes cortes de recursos. Dentro do PNAE - Programa Nacional de Atividades Espaciais, destacam-se o projeto binacional CBERS - China-Brazil Earth Resources Satellites, para o qual foram destinados cerca de R $\$ 33$ milhões entre 1998/99; e a Missão Espacial Completa Brasileira-MECB, que contém três vertentes: o desenvolvimento e o lançamento de cinco satélites; o desenvolvimento do VLS - Veículo Lançador de Satélites; e a participação brasileira no projeto da Estação Espacial Internacional (ISS), em que estão previstos investimentos da ordem de US\$ 150 milhões para o fornecimento de suprimentos pela subcontratação de empresas nacionais intermediada pelo Inpe, a maior parte delas sediada em São José dos Campos.

Os demais institutos federais têm uma vocação setorial. Eles estão ligados à Embrapa e ao Ministério de Ciência e Tecnologia, no qual destaca-se o Centro de Tecnologia de Informática. Esse instituto sofreu cortes profundos no seu orçamento de 1997 para 1998, uma queda de 14,1 para 5,8 milhões de reais. Os institutos federais setoriais, em São Paulo, têm dimensão muito menor que os das áreas estratégicas. Na segunda metade da década de 90, o contingente de institutos federais se ampliou com a instalação do Laboratório de Luz Sincroton (LNLS) e a transformação do $\mathrm{CPqD}$ numa fundação de direito privado após a privatização do sistema Telebrás. O LNLS se destaca no cenário paulista como um instituto federal fundamentalmente voltado para a pesquisa básica. Os institutos estaduais têm um perfil bastante diferenciado em relação aos institutos federais. Eles têm uma vocação para áreas sociais ou para setores econômicos com forte dimensão social, como a agricultura. Nessas funções predomina o gasto estadual sobre o gasto federal, o que está longe de se repetir nos demais Estados da Federação. Com efeito, segundo os dados da Fapesp, o gasto da Secretaria da Agricultura com seus institutos de pesquisa (US\$ 33 milhões, em 1995) é mais de três vezes superior ao gasto do Ministério da Agricultura com os institutos da
Embrapa no Estado. Tal comparação é ainda mais significativa no campo da saúde, onde não há instituto federal de pesquisa.

Os institutos da Secretaria da Saúde são responsáveis por mais da metade dos gastos dos institutos estaduais em ciência e tecnologia. A rede de institutos estaduais em saúde conta com instituições de muito prestígio nacional e internacional, como o Instituto Butantã, o Instituto Adolfo Lutz, o Instituto Emílio Ribas e o Instituto Dante Pazzanese de Cardiologia, entre os mais importantes. Essa rede tem uma dimensão superior à da Fundação Oswaldo Cruz, que é a maior instituição de pesquisa em saúde do país e pertence ao governo federal.

Em segundo lugar, com $20 \%$ do gasto de C\&T estadual em institutos de pesquisa, se posicionam os institutos ligados à Secretaria de Agricultura. Nesse segmento, conta-se também com instituições de renome como o Instituto Agronômico de Campinas, a mais antiga instituição de pesquisa agrícola do país, o Instituto Biológico e o Instituto de Tecnologia de Alimentos, entre os mais importantes. As Secretarias do Meio Ambiente e de Ciência e Tecnologia se posicionam em terceiro lugar, com aproximadamente $13 \%$ dos gastos estaduais. O meio ambiente é uma área com vocação social na qual é muito importante a atuação do governo estadual por meio de seus institutos de pesquisa. A Secretaria de Ciência e Tecnologia abriga fundamentalmente o Instituto de Pesquisa Tecnológica (IPT), uma instituição um pouco diferente das anteriores por atender à indústria e possuir uma vocação multissetorial. No IPT funcionam 12 divisões direcionadas a diversos setores da indústria.

Essa rede de instituições federais e estaduais de pesquisa atravessa um importante processo de redefinição de funções e de mudança de relacionamento com o poder público. As instituições com vocação setorial, voltadas principalmente para a indústria, estão sofrendo importantes cortes ou têm perspectivas de cortes orçamentários. Os Governos Estadual e Federal estão claramente sinalizando para a necessidade de buscar fundos em recursos públicos concorrenciais (verbas de agências de fomento e fundos) ou privados. Como exemplo dessa transformação, podemos oferecer o exemplo do CPqD (Centro de Pesquisa e Desenvolvimento), cujos recursos garantidos deverão provir, num futuro breve, de uma parcela do Fundo de Desenvolvimento Tecnológico de Telecomunicações e, em maior medida, do mesmo fundo, só que de forma concorrencial, ou então de contratos com empresas privadas e/ou com a Anatel. O mesmo pode ser dito do IPT 
que está em acelerado processo de transformação e para o qual as fontes extraorçamentárias já são responsáveis por aproximadamente $50 \%$ dos recursos. Essa transformação dos institutos de pesquisa industrial em direção ao mercado, se bem pode aumentar a interação de certos setores desses institutos com a economia e a sociedade, também apresenta a ameaça de comprometer a manutenção de determinadas competências científicas e tecnológicas acumuladas ao longo de décadas, voltadas para a pesquisa de mais longo prazo, e que por essa razão não costumam ser rentáveis. Mais grave ainda será quando a atividade de pesquisa - principal missão desses institutos vier a ser substituída pela prestação remunerada de serviços que não acarretam acúmulo de conhecimento (SalesFilho, 2000).

\section{Agências Federais e Estaduais de Fomento como Instrumentos para Desenvolver a Pesquisa}

As agências de fomento têm um papel muito importante no financiamento da pesquisa científica. Elas canalizam recursos financeiros, grande parte a fundo perdido, para as atividades de pesquisa de universidades e institutos de pesquisa localizados no Estado. Ultimamente, essas agências de fomento vêm destinando uma parcela crescente dos seus recursos, embora ainda pequena, para as empresas que fazem pesquisa tecnológica sozinhas ou em parcerias com instituições públicas de pesquisa. O caráter concorrencial é uma característica central do financiamento dessas agências, estimulando as instituições que executam a pesquisa (universidades, institutos e empresas) a competir entre si na busca de maior excelência e produtividade acadêmica e científica. Para orientar a alocação de seus recursos, essas agências se apóiam em sistemas de avaliação que, na maior parte, funcionam entre os pares, reconhecidamente os mais eficientes de acordo com a experiência internacional. O sistema concorrencial responde, também, adequadamente a políticas de orientação de recursos e de definição de prioridades.

O sistema de fomento, no plano nacional, está quase todo concentrado nas agências federais. Somente muito recentemente vem se consolidando uma rede de agências de fomento estaduais. Entretanto, o Estado de São Paulo é pioneiro no estabelecimento de uma agência de fomento à $P \& D$, com a criação da Fapesp em 1962. Dada a riqueza desse Estado, que é responsável por $36 \%$ do PIB brasileiro, e uma legislação respeitada pelas autoridades que lhe garante por força de lei uma parcela fixa da arrecadação tributária, a Fapesp desfruta de uma situação privilegiada entre as demais fundações estaduais nacionais. Essa situação foi ainda incrementada a partir da metade da década de 90, quando o governo estadual passou a cumprir a nova Constituição Estadual que determina que a parcela destinada à Fundação passe para $1 \%$ da arrecadação do ICMS.

Ainda assim, os recursos das agências federais continuam sendo mais importantes no âmbito estadual. Segundo os dados elaborados pela Fapesp, as agências federais eram responsáveis por $66 \%$ do total dos recursos destinados ao fomento de pesquisa no Estado de São Paulo. Por outro lado, os recursos alocados no Estado representavam, em 1995, $31 \%$ do total dos recursos aplicados pelas agências federais de fomento. Esses recursos se repartem basicamente entre CNPq (Conselho Nacional de Pesquisas) e Capes (Coordenação de Aperfeiçoamento do Pessoal do Ensino Superior), cabendo apenas uma pequena parcela à Finep (Financiadora de Estudos e Projetos), responsável primordialmente pelo financiamento de caráter tecnológico. Os recursos do CNPq e da Capes se destinam basicamente ao pagamento de bolsas para estudantes de pós-graduação e pesquisadores. Pela sua importância dentro do sistema C\&T estadual, as universidades públicas estaduais paulistas são responsáveis pela captação de $80 \%$ dos recursos das agências de fomento federais destinados ao Estado de São Paulo. $\mathrm{O}$ restante se divide entre as universidades federais, $12,7 \%$, e as demais instituições públicas de pesquisa.

O perfil de atuação da Fapesp é bastante distinto das agências federais e, de certa forma, complementar. Com efeito, os recursos da Fapesp se destinam em grande medida ao apoio à pesquisa e à infra-estrutura (equipamentos, instrumentos, livros e software) dessas instituições. Os recursos oriundos da Fapesp são hoje responsáveis por praticamente $85,8 \%$ dos recursos destinados à pesquisa $\mathrm{e}$ à infra-estrutura das universidades e institutos de pesquisa paulistas. Note-se que os financiamentos da Fapesp também beneficiam os institutos federais localizados em São Paulo (Tabela 3).

A Fapesp tem tido um papel decisivo na manutenção e ampliação dos laboratórios e das atividades de pesquisa das universidades e, em menor medida, dos institutos de pesquisa do Estado de São Paulo durante a década de 90. Esse apoio se mostrou ainda mais decisivo porque as agências federais foram incapazes de desenvolver recursos significativos para sustentar o custeio e a compra de equipamentos de pesquisa. Sem o apoio da Fapesp, é muito 
TABELA 3

Repartição das Verbas de Fomento à Pesquisa, segundo Tipo de Auxílio

Estado de São Paulo - 1995

\begin{tabular}{|c|c|c|c|c|c|c|}
\hline \multirow{2}{*}{ Tipo de Auxílio } & \multicolumn{2}{|l|}{ Fapesp } & \multicolumn{2}{|c|}{ Agências Federais (1) } & \multicolumn{2}{|l|}{ Total } \\
\hline & Em US\$ milhões de1995 & $\%$ & Em US\$ milhões de 1995 & $\%$ & Em US\$ milhões de 1995 & $\%$ \\
\hline Total & 135,7 & 33,8 & 265,4 & 66,2 & 401,2 & 100,0 \\
\hline Auxílios e Infra-Estrutura & 111,9 & 85,8 & 18,5 & 14,2 & 130,5 & 100,0 \\
\hline Bolsas de Estudo & 23,8 & 8,8 & 246,9 & 91,2 & 270,7 & 100,0 \\
\hline
\end{tabular}

Fonte: Fapesp

(1) Inclui CNPq, Capes e Finep.

TABELA 4

Gastos e Recursos Humanos de Nível Superior no Sistema Público de C\&T

Estado de São Paulo - 1995

\begin{tabular}{|c|c|c|c|c|}
\hline \multirow{2}{*}{ Sistema Público de C\&T } & \multicolumn{2}{|c|}{ Dispêndios } & \multicolumn{2}{|c|}{ Docentes, Engenheiros e Pesquisadores } \\
\hline & Em US\$ milhões de 1995 & $\%$ & Números Absolutos & $\%$ \\
\hline Total & 2.515 & 100 & 14.717 & 100 \\
\hline Universidades Estaduais & 1.316 & 52 & 9.861 & 67 \\
\hline Universidades Federais & 261 & 10 & 1.251 & 9 \\
\hline Institutos de Pesquisa Estaduais & 199 & 8 & 2.342 & 16 \\
\hline Institutos de Pesquisa Federais & 338 & 13 & 1.262 & 8 \\
\hline Agências de Fomento Federais & 265 & 11 & - & - \\
\hline Fapesp & 136 & 6 & - & - \\
\hline
\end{tabular}

Fonte: Fapesp, Capes, CNPq, MEC, USP, Unicamp, Unesp.

provável que uma parcela substancial da capacitação científica do Estado de São Paulo ficaria comprometida.

Em função do declínio dos recursos provenientes da esfera federal, que se acentua a partir de 1997, esse frágil equilíbrio está sendo colocado em questão. As verbas federais para as bolsas estão se reduzindo em valores reais e números absolutos. Os gastos do Ministério de Ciência e Tecnologia com C\&T caíram de 1,475 bilhão em 1997 para 708 milhões de reais em 1998, ou seja, menos da metade. O CNPq, que era ainda em 1995 a principal fonte de verbas de fomento federais para o Estado de São Paulo, viu seu orçamento reduzir-se de 770 milhões de reais em 1994 para 450 milhões em 1998, levando a comunidade acadêmica a exercer uma pressão crescente sobre a Fapesp para atender às necessidades de bolsas dos cursos de pós-graduação, o que a Fundação vem conseguindo suprir parcialmente, sob o risco de reduzir seu papel na renovação da infra-estrutura.

Além de suas formas tradicionais de atuação, a Fapesp tem inovado, diversificando consideravelmente suas modalidades de apoio. Nos últimos anos surgiram novas linhas de incentivo destinadas aos laboratórios públicos de pesquisa, não mais por meio do chamado "balcão", mas de programas especiais de pesquisa direcionados a problemas de grande relevância socioeconômica para o Estado, como o Genoma-Fapesp, o Biota-Fapesp e o programa de Pesquisas em Políticas Públicas. O programa Genoma-Fapesp se subdivide hoje em diversos projetos destinados a mapear o código genético de bactérias que afetam a cultura de frutas cítricas no Estado de São Paulo e da cana-de-açúcar. O projeto da Xylella fastidiosa, destinado a mapear o código genético do amarelinho, praga que ataca a laranja e já provocou grandes prejuízos, recebeu recursos da ordem de US\$ 15 milhões e contou com a colaboração de universidades e institutos públicos de pesquisa paulistas. A Fapesp em conjunto com o Instituto Ludwig de pesquisas sobre o câncer, investiu cerca de US\$ 20 milhões no programa Genoma do Câncer visando o seqüenciamento dos genes ativos dos tumores do câncer. Com base nesses esforços o Brasil é hoje o segundo país produtor de seqüências derivadas do câncer e o terceiro maior do mundo em termos de ESTs humanas (Expressed Sequence Tags).

\section{Anatomia do Sistema Público de C\&T Paulistas}

Podemos fazer, neste ponto, um balanço que consolide os principais aspectos do Sistema Público de C\&T 
paulistas. Como se observa na Tabela 4, esse sistema despendeu US\$2,5 bilhões, em 1995, na execução de atividades de C\&T. Esse montante correspondia a $1,11 \%$ do PIB paulista e a cerca de $46 \%$ do valor do dispêndio interno bruto em C\&T financiado pelo setor público no Brasil, valor superestimado, uma vez que a totalidade dos recursos orçamentários das universidades foram apropriados como gastos em C\&T. Um exercício que seguisse o procedimento de vários países e aplicasse um redutor de $50 \%$ aos dispêndios em educação superior reduziria o total dos gastos do Sistema Público de C\&T paulista para US\$ 1,72 bilhão $-0,76 \%$ do PIB paulista (muito próximo da relação gasto público em C\&T/PIB nacional) e $32 \%$ do dispêndio em C\&T financiado pelo setor público.

Esses números evidenciam a importância do sistema de C\&T paulista no cenário nacional dos insumos aplicados à C\&T. Para que se tenha uma idéia da importância de São Paulo no esforço de pesquisa nacional, basta mencionar que, enquanto o número de pesquisadores em São Paulo (14.717) representa pouco mais de um quinto (23\%) do total nacional (65 mil), em 1995, a C\&T executada em território paulista envolve recursos equivalentes a pelo menos um terço dos recursos para pesquisa executados pelo governo federal.

\section{CRESCIMENTO DA PRODUÇÃO CIENTÍFICA}

O conjunto das universidades estaduais paulistas responde por boa parte da produção científica brasileira. Em 1995, São Paulo respondia por cerca da metade das publicações científicas nacionais $(49 \%$, segundo dados da Capes) e por dois terços delas na área de ciências da saúde, em que o Estado se especializa (Tabela 5).

A formação de recursos humanos para pesquisa no país teve como plataforma impulsora o Programa Nacional de Bolsas para a Pós-Graduação, que envolveu a ação conjunta da Capes e do CNPq, mas em São Paulo o fortaleci- mento se deu com um expressivo número de bolsas concedidas pela Fapesp. Esse programa não apenas permite a titulação de docentes de todo o Brasil, mas é um mecanismo fundamental para a difusão de centros emergentes de pesquisa pelo país. A formação de docentes e pesquisadores de alto nível em São Paulo tem reflexos que se expandem para muito além da fronteira do Estado. O gasto com ciência e tecnologia em São Paulo representa 32,0\% do dispêndio federal; os recursos humanos para pesquisa no setor público no Estado (docentes em tempo integral das universidades e pesquisadores dos institutos de pesquisa estaduais e federais localizados em São Paulo) equivalem a 22,8\% dos recursos nacionais. Quando se incluem os pesquisadores titulados nas empresas industriais, o percentual de São Paulo sobre o total nacional é de $22 \%$ (Tabela 6).

A produção científica paulista por 100 mil habitantes, é maior que o dobro da média nacional. Com base em publicações internacionais indexadas, a produção científica paulista representa quase $60 \%$ da média nacional, sendo de aproximadamente $75 \%$ na área médica (Tabela 7).

Além da produção científica, o Estado de São Paulo assume clara liderança na formação em nível de pós-graduação em suas universidades. Assim, das 11.925 dissertações de mestrado defendidas em 1997 em todo o Brasil, 3.846, quase um terço $(32,2 \%)$ delas, foram produzidas nas universidades públicas no Estado de São Paulo. Na produção de teses de doutorado a expressão das universidades públicas localizadas no Estado de São Paulo se destaca mais ainda no cenário nacional: em 1997, do total de 3.604 teses defendidas no país, 2.322 foram defendidas nas universidades paulistas, representando $64,4 \%$ do total nacional.

\section{Integração entre Empresas e Setor Público de C\&T}

As seções anteriores evidenciaram alguns traços, contrastantes, do sistema estadual de inovação paulista.

TABELA 5

Produção Científica Total e em Ciências da Saúde

Brasil - 1995

\begin{tabular}{lcccc}
\hline & \multicolumn{2}{c}{ Ciências da Saúde } & \multicolumn{2}{c}{ Total } \\
\cline { 2 - 5 } Regiões & $\begin{array}{c}\text { Publicações } \\
\text { no Pais }\end{array}$ & $\begin{array}{c}\text { Publicações } \\
\text { no Exterior }\end{array}$ & $\begin{array}{c}\text { Publicações } \\
\text { no País }\end{array}$ & $\begin{array}{c}\text { Publicações } \\
\text { no Exterior }\end{array}$ \\
\hline Brasil & 9.939 & 2.529 & 31.442 & 14.197 \\
Sudeste & 8.121 & 1.965 & 22.522 & 10.317 \\
São Paulo & 6.629 & 1.627 & 15.666 & 6.708 \\
São Paulo/Brasil (\%) & 66,70 & 64,33 & 49,83 & 47,25 \\
\hline
\end{tabular}

Fonte: Capes. 
TABELA 6

Insumos e Produtos da Atividade Científica e Tecnológica

Estado de São Paulo e Brasil - 1995

\begin{tabular}{lccc}
\hline Indicadores & São Paulo & Brasil & São Paulo/Brasil (\%) \\
\hline Indicadores de Insumo de C\&T & & & \\
Dispêndio em C\&T (US\$ milhões) & $1.720,2$ & $5.357,00$ & 32,0 \\
Recursos Humanos para Pesquisa - Setor Público & 14.717 & 65.007 & 22,6 \\
RH para Pesquisa - Setor Público e Privado & 16.057 & 72.926 & 22,0 \\
Agências - Bolsas e Auxílios - Fed. Est. (US\$ milhões) & $(1) \quad 401,21$ & 867,58 & 46,2 \\
Indicadores de Produto ou de Impacto de C\&T & & 45.639 & 49,0 \\
Produção Científica (Capes) & 22.374 & 12.468 & 66,2 \\
Produção Científica - Ciências da Saúde & 8.256 & 7.309 & 50,6 \\
Patentes Solicitadas por Residentes no Brasil & 3.701 & 1.462 & 65,1 \\
Patentes Concedidas a Residentes no Brasil & 952 & 3.604 & 64,4 \\
Teses de Doutorado Defendidas em 1997 & 2.322 & 11.925 & 32,2 \\
Dissertações de Mestrado Defendidas em 1997 & 3.846 & & \\
\hline Font Capes CNPq Fapespo
\end{tabular}

Fonte: Capes; CNPq e Fapesp.

(1) Referem-se a US\$265,44 milhões em bolsas e auxílios da Capes e CNPq e US\$135,77 milhões da Fapesp.

TABELA 7

Artigos Científicos, segundo Áreas de Conhecimento Brasil - 1981/1993

\begin{tabular}{|c|c|c|c|c|c|}
\hline Áreas de Conhecimento & Brasil & 10 Centros & Centros SP & Fora SP & SP/10 Centros (\%) \\
\hline Total & 47.184 & 24.711 & 14.253 & 10.458 & 57,68 \\
\hline Ciências Biológicas & 8.338 & 2.449 & 1.151 & 1.298 & 47,00 \\
\hline Ciências Biomédicas & 12.130 & 7.043 & 4.042 & 3.001 & 57,39 \\
\hline Medicina & 5.639 & 2.680 & 1.994 & 686 & 74,40 \\
\hline Medicina Social & 1.206 & 574 & 435 & 139 & 75,78 \\
\hline Química & 3.976 & 2.819 & 1.929 & 890 & 68,43 \\
\hline Física & 8.568 & 5.385 & 2.906 & 2.479 & 53,96 \\
\hline Matemática & 1.066 & 624 & 316 & 308 & 50,64 \\
\hline Engenharia & 3.069 & 1.184 & 549 & 635 & 46,37 \\
\hline Ciências da Terra & 990 & 357 & 171 & 186 & 47,90 \\
\hline Meio Ambiente & 848 & 225 & 99 & 126 & 44,00 \\
\hline Humanas e Artes & 1.354 & 645 & 299 & 346 & 46,36 \\
\hline Sem Especificação & & 726 & 362 & 364 & 49,86 \\
\hline
\end{tabular}

Fonte: Meiss e Leta (1996), com base nas informações do Science Citation Index, ISI.

Foram ressaltadas a relativa grandeza e o amadurecimento do sistema público de C\&T paulista, que se expressa pelo desenvolvimento das universidades mais importantes do país e uma rede de institutos de pesquisa de porte considerável, além do peso da produção científica paulista na atividade científica nacional.

Em países de industrialização recente, como o Brasil, a maior parte das atividades ligadas à inovação refere-se à difusão, adaptação e melhoria de tecnologias de produtos e processos já existentes, mais que à geração de novas tecnologias. Freqüentemente essas atividades são realizadas por funções de rotina como o controle de qualidade, a engenharia de manutenção e a engenharia de manufatura, ou ainda no âmbito de pequenos grupos de engenharia de produto e processo, em vez de laboratórios de P\&D for- malmente organizados. No entanto, nos países de industrialização recente que deram prioridade ao alcance de maior autonomia tecnológica - isto é, a geração endógena de tecnologias novas a partir da absorção completa de tecnologias importadas -, a função de Pesquisa e Desenvolvimento empresarial cresceu progressivamente, até atingir proporção elevada no total realizado pelo país. Esse é, por exemplo, o caso da Coréia do Sul, em que a participação empresarial no dispêndio total em Pesquisa e Desenvolvimento do país superou 75\% em 1995 - nível superior ao de países mais industrializados, como o Japão $(67 \%)$, os EUA (62\%) e a Alemanha (59\%).

Em contraste, nos países latino-americanos mais industrializados, como o Brasil, o México e a Argentina, as taxas históricas de participação das empresas nos dispên- 
dios nacionais em P\&D mantiveram-se em torno de $20 \%$, em média. Mesmo o recente crescimento dos gastos em P\&D das empresas brasileiras, identificado pelos indicadores do $\mathrm{MCT}$, não levou a participação do $\mathrm{P} \& \mathrm{D}$ privado a mais de $31 \%$ do dispêndio total com P\&D no Brasil (dados de 1995). Isso se deve a um conjunto de características da estrutura industrial do país, que será discutido adiante, e determina não apenas níveis de gastos mais modestos na $\mathrm{P} \& \mathrm{D}$ industrial, como a concentração radical da $\mathrm{P} \& \mathrm{D}$ das empresas em atividades de desenvolvimento, com baixa participação da pesquisa. Essa última característica não favorece a cooperação empresas/sistema público de pesquisa.

Nesse contexto, as relações de cooperação entre o setor privado e o sistema público de C\&T são bastante incipientes, mas com alguns exemplos pontuais notáveis. Essa é possivelmente a maior vulnerabilidade do sistema de C\&T paulista, pois significa que o potencial de conhecimento científico e tecnológico acumulado pelo investimento público em C\&T não se traduz em capacitação tecnológica e de inovação no setor produtivo, ou seja, não se converte em benefícios econômicos.

\section{Inovação Tecnológica nas Empresas Industriais ${ }^{1}$}

As empresas produtoras de bens e serviços são parte crucial do sistema de inovação tecnológica nos países industrializados. São pelas atividades de inovação das empresas que os conhecimentos científico e tecnológico se transformam em inovações de produtos e processos, que dão sustentação real à competitividade das empresas nos mercados em que atuam. Sendo o Estado de São Paulo responsável por cerca de $50 \%$ do produto industrial brasileiro, e onde se concentram os núcleos da maior parte dos setores mais dinâmicos, a questão das atividades tecnológicas das empresas e das suas relações com o sistema público de C\&T é de importância decisiva para seu futuro. Essa avaliação pôde ser realizada devido à disponibilidade de informações sobre inovação tecnológica da indústria paulista produzidas pela Paep/Seade - Pesquisa da Atividade Econômica Paulista, que coletou informações sobre atividades de inovação tecnológica referentes ao triênio 1994/1996, em mais de 10 mil empresas industriais, de todos os portes (acima de cinco empregados), baseando-se nas diretrizes metodológicas recomendadas pelo Manual de Oslo da OECD, o que possibilitou a comparação com as práticas de outros países. A seguir sintetizamos as principais conclusões da pesquisa.

\section{Desempenho Inovador}

As empresas industriais no Estado de São Paulo apresentaram um desempenho significativo na introdução de inovações tecnológicas, em termos relativos, $25 \%$ das empresas introduziram produtos tecnologicamente modificados (inteiramente novos ou aperfeiçoados) e/ou processos tecnologicamente aperfeiçoados ou novos, no período de 1994-1996. Comparativamente com outros países, a taxa de inovação da indústria regional não se distancia tão significativamente das taxas calculadas com base em pesquisas de inovação instituídas em países que adotaram os mesmos procedimentos metodológicos de mensuração e apresentam uma estrutura produtiva com características tecnológicas e de diversificação semelhantes ou próximas às do Estado de São Paulo, como o caso da Espanha e da Austrália.

A pesquisa de inovação espanhola (INE apud SanzMenédez e Garcia, 1998), por exemplo, cujo período de referência é 1992-94, feita a partir de uma amostra de 20 e mais empregados, captou uma taxa de inovação da ordem de $29,5 \%$. O survey de inovação realizado na Austrália, para o quadriênio 1994-1997 revelou que a proporção de empresas inovadoras correspondia a uma taxa de inovação de $26 \%$. Relativamente próximas, portanto, à taxa de inovação das empresas paulistas. Entretanto, quando confrontada a taxa de inovação da Paep com a de outros países de industrialização madura e mais avançada, como Itália, França e Alemanha, evidencia-se uma distância substancial entre os níveis de performance dessas taxas. O survey aplicado na Itália (Archibugi, Evangelista e Simonetti, 1995), abrangendo o período 1990-92, em empresas com mais de 20 empregados, calcula uma taxa de inovação em torno de $33 \%$. Na França, a pesquisa de inovação Sessi (François e Favre, 2000), baseada em uma amostra com empresas de mais de 20 empregados, captou uma taxa de $41 \%$ de empresas industriais que introduziram algum tipo de inovação, no período de 1991-92. E, por fim, a pesquisa alemã (Licht, Schnell e Stahl, 1995) feita a partir de um universo amostral composto por empresas de mais de cinco empregados, com periodicidade anual, identificou um percentual de 53\% de empresas que introduziram inovações tecnológicas.

A propensão a inovar tem relação direta com o tamanho da empresa. Entre as pequenas empresas (5 a 99 empregados), a parcela de empresas inovadoras é de $22 \%$, subindo para $52 \%$ e $59 \%$ nas médias (100 a 499 empregados), e alcançando a taxa de $70 \%$ entre as grandes empre- 
sas industriais (500 empregados e mais). Portanto, devido a sua maior disponibilidade de recursos financeiros, tecnológicos, humanos e gerenciais, as grandes empresas têm demonstrado maior capacidade para inovar, isto é, lançar novos produtos e adotar novos processos, colocando-se em melhor posição para proteger ou incrementar sua competitividade. Essa conclusão reforça, agora pelo lado das capacitações para inovar, o diagnóstico da fragilidade das pequenas empresas. Outro aspecto crucial a ser analisado na economia paulista é a origem do capital das empresas inovadoras, porque fazem parte de uma economia nacional com grande participação do capital estrangeiro nos setores industriais de maior peso econômico. As empresas controladas integral ou parcialmente por capitais estrangeiros apresentam maior propensão para inovar que as empresas controladas integralmente por capital nacional. Entre as grandes empresas (500 e mais empregados), $81 \%$ daquelas controladas por capital estrangeiro são inovadoras, ao passo que $65 \%$ das controladas por capital nacional são inovadoras. ${ }^{2}$

No Brasil, as multinacionais incorporam essas inovações adaptando-as às características do mercado brasileiro ou a limitações técnicas determinadas pelo fornecimento de matérias-primas e componentes locais. Não obstante, a atividade de adaptação de produtos e processos realizada por empresas com participação estrangeira é responsável pelo emprego da maior parcela de engenheiros e outros profissionais de nível superior que atuam em pesquisa e desenvolvimento na indústria paulista.

\section{ESFORÇO DE INOVAÇÃO}

A avaliação dos esforços (investimentos) realizados pelas empresas paulistas para alcançar as taxas de inovação, discutidas anteriormente, revela a relativa fragilidade do processo de capacitação tecnológica desenvolvido no Estado (como, de resto, no Brasil). Em primeiro lugar, observa-se que, apesar do notável desempenho inovador de novos produtos e processos no período 1994/1996, as indústrias do Estado de São Paulo não realizaram esforço de P\&D compatível com tal performance. Em segundo lugar, esse fenômeno está associado ao fato de a estratégia tecnológica das empresas privilegiar o incremento dos fluxos de importação de tecnologia, sem acompanhar tal esforço com investimentos significativos em processos de absorção dessas tecnologias. Essa estratégia contribui para explicar a baixa interação entre as empresas paulistas e o sistema público de C\&T.

\section{Atividades de P\&D}

Segundo informações da Paep/Seade, em 1996 havia 8.865 profissionais de nível superior trabalhando em atividades de $\mathrm{P} \& \mathrm{D}$, em 3.422 empresas industriais paulistas, com 100 e mais empregados, que executavam essas atividades. Portanto, a média de profissionais de nível superior nessas empresas era de 2,5. Nota-se que o esforço em $\mathrm{P} \& \mathrm{D}$ é pequeno quando comparado com os esforços das indústrias de países mais desenvolvidos. A comparação aqui é feita entre o Estado de São Paulo e outros países devido a não haver informação equivalente, baseada em pesquisa amostral representativa, que permita conhecer o volume de recursos humanos empregados na $P \& D$ industrial brasileira. Em termos absolutos, o volume de pessoal de nível superior (em sua maior parte engenheiros) empregado em P\&D em São Paulo é superior ao da Austrália e Espanha. No entanto, quando se analisa o emprego industrial total, percebe-se que o indicador de intensidade de $\mathrm{P} \& \mathrm{D}$ australiano $(0,763)$ é o dobro do brasileiro. Brasil e Espanha, por sua vez, encontram-se muito distantes dos países europeus com maior densidade (França e Alemanha) e mais ainda dos países líderes (Japão e Estados Unidos). Não obstante, a posição do Estado de São Paulo (e brasileira) é de liderança na América Latina (Tabela 8 ), uma vez que a posição mexicana é próxima da argentina.

Em resumo, pode-se dizer que o esforço em $P \& D$ industrial feito pela economia paulista, embora apresente um volume que o coloca em primeiro lugar na América Latina, está muito aquém daquele feito pelos países industrializados, inclusive países de industrialização recente como Coréia do Sul e Taiwan. ${ }^{3}$ Em outros termos, o bom desempenho da indústria quanto à taxa de inovação não dependeu primordialmente do esforço interno em P\&D. $\mathrm{O}$ entendimento desse fenômeno requer uma avaliação mais detalhada das características estruturais do processo de inovação na economia paulista (e brasileira).

A recente ampliação da internacionalização da economia brasileira (desnacionalização) aprofundou uma característica do processo de inovação industrial que já era dominante em períodos anteriores. Empresas localizadas no Brasil estão propensas a realizar gastos na importação de tecnologias e no P\&D interno necessário para adaptálas às condições brasileiras (condições de mercado ou matérias-primas). Isto se verifica no significativo crescimento recente das importações de tecnologia no Brasil, que serão examinadas adiante. No entanto, as empresas 
TABELA 8

Pessoal de Nível Superior Empregado em Atividades de P\&D na Indústria de Transformação

Países Selecionados - 1993-1996

\begin{tabular}{lccc}
\hline Países & Anos & $\begin{array}{c}\text { Empregados de Nível } \\
\text { Superior em P\&D (1) }\end{array}$ & $\begin{array}{c}\text { Empregados de Nível Superior em P\&D/ } \\
\text { Pessoal Ocupado na Indústria X 100 }\end{array}$ \\
\hline Brasil (Estado de São Paulo) (2) & 1996 & 8.865 & 0,382 \\
México & 1995 & 1.339 & 0,026 \\
Espanha & 1993 & 8.084 & 0,337 \\
Austrália & 1995 & 8.541 & 0,763 \\
Canadá & 1994 & 22.662 & 1,163 \\
Itália & 1994 & 24.136 & 0,531 \\
Alemanha & 1993 & 121.705 & 1,196 \\
França & 1994 & 55.857 & 1,342 \\
Hungria & 1995 & 2.069 & 0,056 \\
Japão & 1995 & 368.960 & 2,534 \\
Estados Unidos & 1994 & 540.700 & 2,682 \\
\hline
\end{tabular}

Fonte: Fundação Seade. Pesquisa da Atividade Econômica Paulista - Paep; OECD, Basic Science and Technology Statistics, 1997; Yearbook of labour statistics, 1996. (1) Para o Estado de São Paulo, compreende o total de pessoas de nível superior e para os demais países, o número de cientistas e engenheiros alocados nessa atividade. (2) Corresponde a empresas com mais de 99 empregados, somente com sede no Estado de São Paulo.

estão menos propensas a investir na absorção completa das tecnologias importadas, o que lhes permitiria deter conhecimento para desenvolver internamente produtos/ processos significativamente modificados.

No que diz respeito às empresas transnacionais de controle externo, essa estratégia obedece a uma lógica de ampliação de escalas e redução de custos de P\&D. Ao concentrar as atividades de $\mathrm{P} \& \mathrm{D}$ mais ligadas à pesquisa (pesquisa básica e aplicada) em poucos laboratórios de países mais industrializados, essas empresas ganham escala de pesquisa e acesso aos sistemas públicos de C\&T mais avançados do mundo, de onde importam para os mercados emergentes as inovações tecnológicas mais significativas. Não obstante, o desenvolvimento de produtos para mercados locais requer volume considerável de atividades de adaptação/aperfeiçoamento/desenvolvimento - que em geral são concentradas em sedes regionais. Isso explicaria a concentração no Brasil, em particular em São Paulo, das atividades de desenvolvimento de empresas transnacionais, que servem ao conjunto de mercados da América do Sul.

Já as grandes empresas nacionais, embora não disponham da mesma alternativa, seguem comportamento semelhante, confiando fundamentalmente na importação renovada de tecnologia para se manterem competitivas, e concentrando o P\&D local na sustentação das capacidades necessárias para tornar viável este processo de dependência de fluxos externos de conhecimento. $\mathrm{O}$ resultado agregado dessas estratégias tem sido o crescente déficit no balanço de pagamentos tecnológicos (tema do próximo item) e a concentração da $P \& D$ local em atividades de desenvolvimento que pouco demandam do sistema público estadual de C\&T. Um grupo minoritário de empresas que atuam em áreas de média e alta intensidade tecnológica, entretanto, tem estabelecido laços com universidades e institutos de pesquisa. Esse tem sido o caso das indústrias aeronáutica e aeroespacial, química, siderúrgica e de segmentos da indústria eletrônica, nos quais o desenvolvimento de empresas médias de base tecnológica tem se beneficiado da proximidade dos principais centros de pesquisa paulistas. ${ }^{4}$

\section{Importação de Tecnologia pelas Indústrias}

A década de 90 tem sua política econômica caracterizada pela abertura comercial, provocando profundas mudanças nos marcos institucionais que regulam o comércio

TABELA 9

Importação de Tecnologia

Brasil e Estado de São Paulo - 1980-1996

\begin{tabular}{|c|c|c|c|c|}
\hline \multirow[b]{2}{*}{ Anos } & \multicolumn{2}{|c|}{ Brasil } & \multicolumn{2}{|c|}{ Estado de São Paulo } \\
\hline & $\begin{array}{l}\text { Em US\$ mil } \\
\text { de dez./96 }\end{array}$ & $\%$ & $\begin{array}{c}\text { Em US\$ mil } \\
\text { de dez.196 }\end{array}$ & $\%$ \\
\hline 1980 & 593.729 & 100,0 & 131.064 & 22,1 \\
\hline 1985 & 181.770 & 100,0 & 38.357 & 21,1 \\
\hline 1990 & 180.839 & 100,0 & 62.603 & 34,6 \\
\hline 1996 & 801.672 & 100,0 & 372.819 & 46,5 \\
\hline $\begin{array}{l}\text { Total Acumulado } \\
\text { até } 1996 \text { (1) }\end{array}$ & 13.311 .165 & 100,0 & 4.823 .899 & 42,5 \\
\hline
\end{tabular}

Fonte: Firce/Conap (Ufteco 86).

(1) Refere-se ao total das importações de cada Estado até 1996, inclusive. Nota: Valores convertidos pelo IPC dos EUA. 


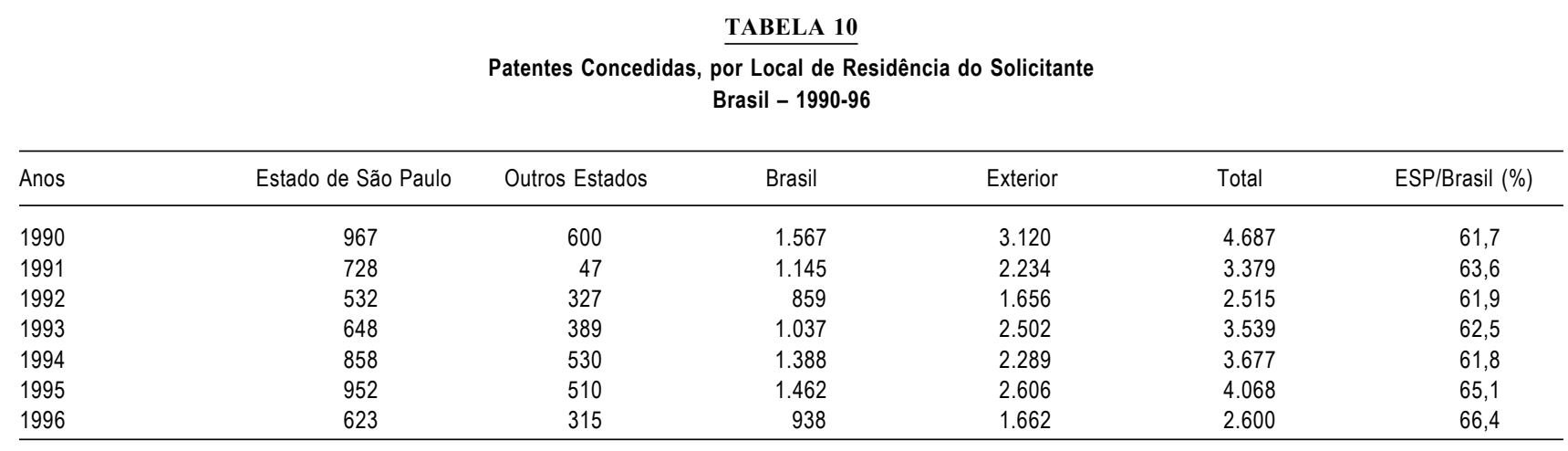

Fonte: Inpi.

de tecnologia. Em dezembro de 1991, a promulgação da Lei ${ }^{\circ} 8.383$ libera a contratação de tecnologia entre subsidiárias locais e suas matrizes no exterior. Em 1996, é aprovada a nova Lei de Propriedade Industrial, que entra em vigor um ano depois, em maio de 1997. Em relação aos contratos de transferência de tecnologia, essa lei suprime a atividade regulatória do Instituto Nacional de Propriedade Industrial (Inpi) - e portanto do Estado - sobre os fluxos tecnológicos.

A partir de 1994, tornam-se marcantes os reflexos das transformações ocorridas tanto na legislação sobre a transferência de tecnologia, quanto nas políticas econômica e de comércio exterior adotadas no período. Conforme se nota na Tabela 9, há um crescimento muito significativo das importações de tecnologia, que saltam do patamar de US\$ 180 milhões, em 1990, para mais de US\$ 800 milhões, em 1996. A indústria que assume a liderança na importação de tecnologia nos anos 90 é a do setor eletroeletrônico, responsável por $13 \%$ do total no período, nos dispêndios com contratos de transferência de tecnologia. O comportamento dos gastos com importação de tecnologia (contratos de assistência técnica, royalties, marcas e patentes, serviços tecnológicos, etc.) no Estado de São Paulo apresenta um crescimento significativo a partir de 90, alcançando 46,5\% das despesas nacionais em 1996. Essa ampliação da participação paulista nas importações de tecnologia possibilitou ao Estado superar o Rio de Janeiro, que até então era o maior importador de tecnologia.

\section{Descompasso entre o Crescimento da Produção Científica e a Estagnação da Geração de Tecnologias}

Uma das maneiras - ainda que imperfeita - para se avaliar a capacidade de geração de tecnologias de uma economia seria por seus indicadores de pedidos e conces- são de patentes. Os países com liderança tecnológica são os que apresentam os mais elevados indicadores de patentes, ainda que nem sempre suas especializações setoriais encontrem na propriedade industrial a melhor maneira de garantir o segredo do negócio. Em linha com o exposto nas seções anteriores, é importante registrar que, embora o grande investimento realizado pelo governo brasileiro (e paulista) nas últimas décadas tenha resultado em drástica elevação dos índices de produção científica nacional, esse crescimento não teve reflexo substancial no crescimento do número de patentes concedidas ou mesmo no nível de relacionamento entre universidades e empresas brasileiras.

As patentes concedidas no Brasil são em número muito reduzido e destinam-se, na maioria das vezes, a legalizar a exploração de tecnologias de propriedade de empresas estrangeiras instaladas no mercado (as patentes concedidas a não-residentes superam aquelas concedidas a residentes) (Tabela 10).

Outra maneira de se medir a produção tecnológica seria pelo coeficiente de inventividade, que representa a razão entre o número de solicitações de patentes por residentes no país e a população desse país. Aqui também o desempenho brasileiro tem sido limitado: o coeficiente nacional, na década de 90 , tem mantido uma média pouco superior a quatro pedidos por 100 mil habitantes, em contraste com países como Taiwan (139/100 mil), Canadá (10/ 100 mil), Itália (14/100 mil), Estados Unidos (47/100 mil) e Suíça (563/100 mil).

Ainda que essa lógica não possa ser atribuída inteiramente a uma falha na política científica e tecnológica (C\&T) do país, pois, como se viu, deriva mais de condições estruturais agravadas pelo processo de globalização, a consciência dessa situação tem levado os responsáveis pela formulação e execução da política C\&T a iniciativas visando criar 
mecanismos de vinculação (a chamada política vinculacionista) entre o sistema público de pesquisa e as empresas, sem que haja ainda evidências fortes de seu sucesso. A precária conformação das redes de pesquisa no Brasil, sua situação de país em via de desenvolvimento e as próprias limitações do processo de interação universidade/empresa nos países centrais são os principais fatores da relativa limitação dessas iniciativas que, em alguns casos, sequer tiveram tempo de maturação para serem avaliadas. Esses pontos são discutidos nos próximos itens.

\section{Sistema Público de C\&T e as Empresas: a baixa demanda de tecnologia nacional}

As empresas de países em desenvolvimento como o Brasil, que adotaram um modelo de industrialização com baixa absorção de conhecimentos tecnológicos, se caracterizam por ter um baixo nível de demanda por insumos provenientes do sistema público de C\&T. As políticas adotadas no passado para reforçar esses elos não foram muito efetivas. Como se viu anteriormente, tanto as filiais de empresas multinacionais como as empresas privadas de capital nacional, costumam estabelecer elos preferenciais com os países desenvolvidos. Mesmo as empresas estatais tinham uma orientação similar, pois preferiam importar a tecnologia já dominada dos países desenvolvidos a assumir o risco de desenvolvê-la localmente. Apenas algumas empresas estatais se destacam no cenário nacional por haverem iniciado políticas visando, de um lado, reforçar as capacitações científicas e tecnológicas existentes nas universidades e, por outro, desenvolver programas voltados para a pesquisa e o desenvolvimento tecnológico.

Essas carências, que são bem conhecidas, logicamente estão presentes, embora atenuadas, no Estado de São Paulo, por ser este o maior Estado industrial e o que reúne o mais amplo acervo de instituições de pesquisa do país. Nesse Estado, existe um grupo - ainda que minoritário - de grandes e médias empresas com forte vocação tecnológica que costumam estabelecer laços com a rede de universidades e institutos estaduais e federais de pesquisa. Além da solidez e da consistência dessas instituições públicas de pesquisa terem sido um pólo de atração para empresas sediadas em outras regiões do país, como é o caso da Petrobras. O Estado de São Paulo reúne também um importante acervo de experiências no qual institutos públicos de pesquisa tiveram um papel decisivo na formação de empresas de base tecnológica. O exemplo mais consis- tente dessa relação de encadeamento é o da formação de um complexo de empresas em torno do CTA e do Inpe voltadas para o setor aeroespacial, cujo caso de maior sucesso e impacto é o da Embraer (Bernardes, 2000a).

De maneira geral, quando elas existem, as relações entre empresa e universidades costumam orientar-se para a necessidade de formação de recursos humanos de alto nível, que muitas vezes compõe os quadros das equipes de engenharia e dos laboratórios de pesquisa dessas empresas. A relação direta com as universidades visando a atividade de inovação é menos freqüente. Já os institutos de pesquisa, por estarem mais voltados para pesquisa tecnológica, exercem um papel mais importante enquanto fonte de informação no processo de inovação.

Mesmo assim, as instituições públicas de pesquisa têm ainda um papel de pouca importância na introdução de inovações, estando posicionadas em oitavo e décimo primeiro lugar, nos casos respectivamente dos institutos públicos de pesquisa e das universidades. Isso evidencia que, no agregado, as relações empresas/sistema público de C\&T são limitadas e frágeis, mesmo no Estado de São Paulo.

Nas últimas décadas as universidades em associação com os poderes locais têm se empenhado em reforçar os elos com as empresas pela implantação de incubadoras de empresas e de pólos tecnológicos. O caso de maior sucesso é o da cidade de São Carlos, onde uma universidade federal e outra estadual desenvolveram uma experiência bem-sucedida de formação de pólo tecnológico. Contudo, por mais bem-sucedida que seja a experiência de incubação, freqüentemente as empresas de base tecnológica enfrentam o problema do mercado de produtos de alta tecnologia que é sempre limitado e depende do gasto público. Com a recente abertura da economia nacional e a maior facilidade para as empresas e a administração pública de importar esses produtos, as empresas incubadas estão tendo de encarar problemas crescentes de sobrevivência. E embora oriundas do meio acadêmico, têm demonstrado uma baixa propensão para manter esses vínculos no momento em que conseguem se afirmar no mercado, revelando que mesmo nesses casos ainda subsiste uma grande dificuldade de relacionamento entre a academia e as empresas de base tecnológica.

\section{Políticas Públicas e Cooperação Universidade/ Institutos com Empresas}

Existe em todos os níveis da Federação uma vontade cada vez mais firme de reforçar os elos entre o sistema 
público de C\&T e as empresas. Essas políticas derivam da constatação de que o sistema público de $C \& T$ já alcançou um estágio de maturidade suficiente que o habilita para ser um importante interlocutor no esforço de inovação das empresas. O governo federal tem se sensibilizado crescentemente com a necessidade de reforçar os elos entre as empresas e as instituições públicas de pesquisa. Alguns programas destinados a apoiar o desenvolvimento tecnológico, e que eram tradicionalmente voltados ao meio acadêmico, passaram a usar como critério a concessão e a associação entre universidades/institutos com empresas. O caso mais importante é o do PADCT (Programa de Apoio ao Desenvolvimento Científico e Tecnológico), que em sua última versão passou a incorporar esse tipo de critério para a concessão de auxílios. O programa, nestes últimos dois anos, sofreu uma severa redução orçamentária passando de um volume de $\mathrm{R} \$ 40$ milhões, em 1998 para R\$ 25 milhões, em 1999.

A Lei $\mathrm{n}^{\circ} 8.661 / 91$ dispõe sobre os incentivos fiscais para capacitação tecnológica da indústria e da agropecuária, com base na execução de Programas de Desenvolvimento Tecnológico Industrial (PDTI) e Programas de Desenvolvimento Tecnológico Agropecuário (PDTA). São programas de investimento das empresas nas atividades de pesquisa e desenvolvimento científico, mediante a criação e manutenção de estrutura de gestão tecnológica permanente ou o estabelecimento de associações entre empresas. Os incentivos fiscais perderam um importante fator de atratividade em virtude da redução de $8 \%$ para $4 \%$ do limite de dedução do Imposto de Renda devido, de valor equivalente à aplicação de alíquota cabível do imposto à soma dos dispêndios em atividades de pesquisa e desenvolvimento tecnológico, industrial e agropecuário. Com o estímulo desse instrumento, durante o ano de 1999, foram aprovados 105 programas, sendo 43 programas localizados em São Paulo, $42 \%$ do total, com a previsão de investimentos, entre o período 1994-2000, da ordem de $\mathrm{R} \$ 3,85$ bilhões com uma renúncia fiscal de R $\$ 1,1$ bilhão para o Brasil (Ministério da Ciência e Tecnologia, 1999). Desse total, as empresas localizadas no Estado de São Paulo foram responsáveis por $49 \%$ dos investimentos em capacitação tecnológica, equivalendo a $R$ \$ 1,9 bilhão, e por $39 \%$ dos incentivos fiscais federais recebidos, ou $\mathrm{R} \$ 418$ milhões. ${ }^{5}$ Uma pesquisa realizada pela Fiesp, no universo das empresas industriais paulistas, sobre a percepção do setor sobre os incentivos fiscais, revelou que $77,0 \%$ dessas empresas tinham conhecimento da Lei ${ }^{\circ} 8.661 / 91$, mas somente $10,0 \%$ delas já a haviam utilizado. Os principais motivos considerados para a baixa utilização são a baixa atratividade da alíquota de renúncia fiscal e a dificuldade de acesso das empresas de base tecnológica e as pequenas e médias empresas à Lei no ${ }^{\circ} 8.661 / 91$. Na prática, as micro, pequenas e médias empresas são pouco beneficiadas pela legislação atual, pois recolhem um valor muito reduzido de Imposto de Renda, que é o principal atrativo da Lei.

A política definida pelo governo também atua em sentido inverso, exigindo que as empresas, quando contempladas por incentivos fiscais, recorram às instituições de pesquisa para a realização de parte do esforço de pesquisa e desenvolvimento tecnológico. O exemplo mais importante dessa política, de maior impacto no Estado de São Paulo, é o da Lei no ${ }^{\circ} .248 / 91$, de informática, que possibilita às empresas desse setor e do setor de equipamentos de telecomunicações, que gastam pelo menos $5 \%$ do seu faturamento anual em $\mathrm{P} \& \mathrm{D}$, descontarem esses recursos do Imposto de Renda. A lei determina que no mínimo $2 \%$ do faturamento seja aplicado em convênios com institutos de pesquisas e entidades brasileiras de ensino. Em 1994, pela Portaria n ${ }^{\circ} 200$, definiu-se como programas prioritários a Rede Nacional de Pesquisa - RNP, o programa Temático Multiinstitucional em Ciência da Computação - ProteM-CC e o Programa Nacional de Software para Exportação - Softex 2000. Todos estes programas são coordenados e operacionalizados pelo CNPq. Em relação à introdução do Softex, a avaliação de um modo geral é positiva. Ele tem duas vertentes de atuação: uma de mercado e outra tecnológica. O programa permitiu o desenvolvimento de novos softwares, gerando emprego em várias micro, pequenas e médias empresas no Brasil. $\mathrm{O}$ acesso e a oferta das linhas de financiamento são considerados relativamente eficientes pelos seus usuários para o desenvolvimento de novos produtos. $\mathrm{Na}$ vertente de mercado, o programa montou quatro escritórios internacionais para subsidiar as vendas externas, 20 núcleos regionais sediados em universidades de diferentes cidades brasileiras, descentralizando suas ações. Quatro deles situam-se nas Regiões Metropolitanas de São Paulo, Campinas, São José dos Campos e São Carlos. Graças a essa lei as empresas beneficiárias no Estado de São Paulo efetivaram aplicações em torno de $\mathrm{R} \$ 600$ milhões em projetos internos de P\&D, representando $67 \%$ das empresas usuárias desses incentivos no país, e efetuaram também gastos em $\mathrm{P} \& \mathrm{D}$ da ordem de $\mathrm{R} \$ 300$ milhões em convênio com instituições de ensino e pesquisa paulistas, $62 \%$ do total dos gastos nacionais (Ministério da Ciência e Tecnologia, 1998) . 
A Fapesp tem inovado também lançando programas orientados para as empresas. O Pite (Parceria para a Inovação Tecnológica) é um programa de parceria entre empresas e instituições de pesquisa paulistas com o intuito de gerar inovações tecnológicas que já havia aprovado até o primeiro semestre de 2000 , cerca de 46 projetos envolvendo a participação de 44 empresas, além de universidades e institutos de pesquisa. O montante de recursos destinados a esses projetos é de 21,6 milhões de reais, $47 \%$ de responsabilidade da Fapesp e o restante das empresas. O Pipe (Programa de Inovação Tecnológica em Pequenas Empresas) serve para financiar, sem nenhuma contrapartida projetos de pesquisa em empresas com no máximo 100 empregados. Até o momento, 122 projetos foram aprovados envolvendo recursos da ordem de 10,6 milhões de reais. Para aproximar os esforços da ciência com a sociedade, a Fapesp lançou o programa Cepid (Programa de Centros de Pesquisa, Inovação e Difusão), que propõe uma nova abordagem da pesquisa científica, em que se privilegia uma visão integrada da atividade científica incentivando a transferência de conhecimento para os setores público e privado e a educação. Esses novos centros contaram com recursos de $\mathrm{R} \$ 15$ milhões anuais para o desenvolvimento de pesquisas multidisciplinares que situam-se na fronteira do conhecimento. Em conjunto com o governo estadual, a Fapesp estabeleceu o programa Parceria para Inovação em Ciência e Tecnologia Aeroespacial (Picta) para apoiar projetos desenvolvidos por universidades e instituições de pesquisas em conjunto com empresas do setor aeroespacial, destinando-lhes recursos de $\mathrm{R} \$ 18$ milhões.

\section{CONCLUSÕES}

O sistema científico do Estado de São Paulo foi resultado de uma ação conjugada bem-sucedida entre os esforços do governo federal na preparação de recursos humanos de alto nível em ciência e tecnologia; a determinação do governo estadual de assegurar um fluxo permanente de recursos para a manutenção de suas universidades reconhecidos centros de excelência acadêmica -; e da pesquisa científica e tecnológica pela Fapesp, responsável pelo financiamento dessas atividades em todas as instituições de pesquisa, públicas e privadas, estaduais ou federais, localizadas no Estado, de acordo com o mérito dos projetos.

O resultado de mais de três décadas de apoio sustentado à pesquisa e à pós-graduação foi transformar as uni- versidades públicas do Estado em centros de organização e irradiação da formação de mestres e doutores para reciclagem do pessoal docente de nível superior em todo o país; formação de pesquisadores para os institutos e centros de pesquisa públicos e privados do país; e para fornecer pessoal para os departamentos de pesquisa e desenvolvimento e engenharia nas empresas industriais. $\mathrm{O}$ produto desse esforço pode ser avaliado pelos seguintes pontos:

- a produção científica realizada dentro do Estado de São Paulo equivale a aproximadamente a metade da produção nacional, dois terços desse total no caso das ciências da saúde;

- as cinco universidades públicas existentes no Estado, três estaduais (USP, Unesp e Unicamp) e duas federais (Unifesp e Federal de São Carlos), são responsáveis por $50 \%$ dos doutores no país;

- o número de patentes solicitadas por residentes em São Paulo é a metade do número de patentes solicitadas por residentes no Brasil, e as patentes concedidas a residentes em São Paulo correspondem a $66 \%$ do total concedido para residentes no país em 1996.

A nova agenda governamental de desenvolvimento tecnológico instituída nos anos 90 redefiniu o enfoque de uma política baseada na oferta da tecnologia para uma política focada na demanda do mercado e a empresa como principal agente do processo de inovação tecnológica. A nova política sinalizou, para os agentes econômicos, o caminho da acumulação e do desenvolvimento tecnológico pela conquista de novos critérios de qualidade e produtividade e pelo esforço tecnológico empresarial. Entretanto, a implementação de uma política tecnológica e de investimentos mais ampla e articulada com o setor produtivo, revigorando a rede de institutos de pesquisa com a construção de instâncias institucionais de coordenação entre os atores e a formação de visões de longo prazo, prossegue sendo elemento de constrangimento em relação ao futuro desenvolvimento tecnológico sustentado.

O Estado de São Paulo, diferencia-se do quadro nacional, devido ao importante papel que o seu sistema institucional de C\&T ocupa, tendo como eixo estruturante as ações virtuosas empreendidas pela Fapesp no apoio às pesquisas científicas acadêmicas e empresariais. Embora o padrão de relacionamento institucional entre institutos e centros de pesquisas universitários seja considerado incipiente, vem se presenciando nas universidades uma interação importante com as empresas industriais inovadoras. 
Uma das principais conclusões deste artigo consiste na identificação de um desequilíbrio no "sistema de inovação paulista", expresso no que denominamos de descompasso entre a expressiva produção científica efetuada nas universidades, baixa participação de cientistas e engenheiros (C\&E) alocados à atividade de $\mathrm{P} \& \mathrm{D}$ e limitada capacitação tecnológica e de atividades de $\mathrm{P} \& \mathrm{D}$ nas empresas paulistas (bastante centralizada na função de desenvolvimento). Além disso, o déficit no balanço das importações e exportações de serviços tecnológicos e o tímido desempenho do Estado (e do país) no patenteamento de inovações tecnológicas sugerem a proposta síntese deste artigo, em relação ao padrão de inovação da indústria paulista: muita inovação e pouco conhecimento. O maior peso atribuído à importação de tecnologia, sem correspondente esforço de absorção, sugere a continuidade da fragilidade tecnológica das empresas, possivelmente a maior vulnerabilidade do sistema de C\&T paulista, pois significa que o potencial de conhecimento científico e tecnológico acumulado pelo investimento público em $\mathrm{C} \& \mathrm{~T}$ não tem se traduzido em capacitação tecnológica e de inovação no setor produtivo, ou seja, em resultados econômicos expressivos.

No momento em que a interação universidade/empresa começa a ocupar um espaço crescente na agenda das empresas, das universidades e do próprio governo, pelo crescente conteúdo de conhecimento na formação de valor dos bens e serviços, os países em desenvolvimento como o Brasil ou regiões e setores dinâmicos como a indústria e os serviços do Estado de São Paulo devem incluir em sua agenda de desenvolvimento a preocupação em manter atualizada a base de conhecimentos científicos em âmbito internacional, ao mesmo tempo que deve mobilizar esforços na arquitetura de mecanismos que permitam transformar a prática da produção científica em prol de um programa de desenvolvimento econômico e social. Todavia, criticamos a visão simplista da interação universidade-empresa como panacéia para a resolução das necessidades de financiamento das universidades e das demandas de tecnologias das empresas, considerando que cada uma dessas instituições tem missões e culturas próprias, cabendo à política pública uma função estratégica na busca pelo equilíbrio entre demanda e oferta tecnológica nessa interação institucional.

A efetividade dessas políticas de C\&T e da inovação não depende apenas dos incentivos governamentais para que se possa realizar a pesquisa de forma associada e cooperativa. $\mathrm{O}$ futuro das empresas inovadoras nacionais é estigmatizado por um elevado grau de incerteza, tendo em vista que o processo de globalização está intensificando a concorrência e tornando cada vez mais difícil a sua sobrevivência. Por outro lado, as empresas associadas ao capital estrangeiro ou filiais de empresas multinacionais tornaram-se crescentemente clientes desses programas, podendo inaugurar um novo padrão de relacionamento entre políticas governamentais, empresas e instituições de pesquisa. Os elos entre o sistema público de C\&T e as empresas irão depender cada vez mais da atratividade de nossas competências técnico-científicas perante as estratégias globais de empresas multinacionais, o que reforça a importância dos investimentos públicos na manutenção/aperfeiçoamento do sistema de C\&T, na restauração das instituições, modernização da legislação fiscal e das políticas públicas para inovação tecnológica, a fim de promover a inserção competitiva e progressiva das empresas nacionais nas redes de conhecimento globais.

\section{NOTAS}

1. Essa questão é discutida com maior profundidade em um estudo feito por Quadros et alii (1999).

2. Esse resultado pode ser explicado por vários fatores: menor custo do capital das empresas estrangeiras; acesso mais fácil às modalidades de transferência de tecnologia e conhecimento, o que contribui para acelerar a introdução de novos produtos e processos; esses produtos e processos modificados tecnologicamente são originados em países industrializados, nos quais as empresas transnacionais concentram seus principais centros de inovação tecnológica e P\&D.

3. Em 1995, havia mais de 100 mil pessoas ocupadas em P\&D, nas empresas industriais e de serviços da Coréia do Sul, e mais de 60 mil em Taiwan.

4. Da mesma forma, algumas transnacionais (casos como o da Siemens, da Fiat, da Mercedes-Benz e da Rhodia são bem conhecidos) têm ultrapassado os limites de seus próprios muros e transbordado sua atividade de P\&D a fim de envolver alguma forma de cooperação com universidades e institutos, mostrando assim que há espaço para se construir políticas ativas para promover tal integração.

5. Deve-se ressaltar que do montante dos investimentos em P\&D pela Lei no $8.661 / 91$ aprovados em 1999 no Estado de São Paulo, somente a Embraer foi responsável por um programa no valor de $\mathrm{R} \$ 737$ milhões, o maior volume de recursos registrado dentre os programas aprovados no país para esse período (Bernardes, 2000b).

\section{REFERÊNCIAS BIBLIOGRÁFICAS}

ALBURQUERQUE, E.M. "Sistema nacional de inovação no Brasil: uma análise introdutória a partir de dados disponíveis sobre a ciência e a tecnologia". Revista de Economia Politica, v.16, n.3 (63), jul.-set. 1996.

ARCHIBUGI, D.; EVANGELISTA, E. e SIMONETTI, R. "Concentration, firm size and innovation: evidence from innovation costs". Technovation, v.15, n.3, 1995.

ARCHIBUGI, D. e SIRILLI, G. The direct measurement of technological innovation in business. Roma, National Research Council, 2000 (paper).

BELL, D. The coming of pos-industrial society: a venture insocial forescasting. Nova York, Basics Books, 1976.

BERNARDES, R. "A inovação no capitalismo contemporâneo". São Paulo em Perspectiva. São Paulo, Fundação Seade, v.12, n.2, 1998, p.33-45. 
. "O arranjo produtivo da Embraer em São José dos Campos". Seminário Internacional "Arranjos \& Sistemas Locais Produtivos e Novas Políticas de Desenvolvimento Industrial e Tecnológico". Rio de Janeiro, BNDES, 2000a (Lastres, H. e Cassiolato, J. E. orgs.). $2000 \mathrm{~b}$.

. Embraer: Elos entre Estado e Mercado. São Paulo, Hucitec/Fapesp,

BRITO CRUZ, C.H. "Universidade, a empresa e a pesquisa que o país precisa". Texto apresentado ao Grupo Temático de Ciência e Tecnologia do Fórum São Paulo Século XXI da Assembléia Legislativa do Estado de São Paulo, 2000.

CAMPOLINA, C.D. "Global-local: interdependências e desigualdade ou notas para uma política tecnológica e industrial regionalizada no Brasil". International Seminar on Local Productive Clusters and Innovation Systems and New Industrial and Technological Policies. Universidade do Rio de Janeiro, set. 2000 .

CASTELLS, M. The information age: economy, society and culture. Londres, Blackwell, 1997.

CASSIOLATO, J.E. e LASTRES, H. "Inovação, globalização e as novas políticas de desenvolvimento industrial e tecnológico", In: Cluster e sistemas locais de inovação: estudos de casos e avaliação da região de Campinas. Campinas, Unicamp - Instituto de Economia, set. 1999.

."Local systems of innovation in mercosur countries". Industry and Innovation, v.7, n.1, jun. 2000, p.33-54

CHESNAIS, F. "The financing of innovation-related investiment in the contemporany global finance-dominated accumulation regime". International Seminar on Local Productive Clusters and Innovation Systems and New Industrial and Technological Policies. Universidade do Rio de Janeiro, set. 2000 .

COUTINHO, L. e FERRAZ, J.C. (coords.). Estudo da competitividade da indústria brasileira. São Paulo, Papyrus, 1994.

DOSI, G. "The contribution of economic theory to the understanding of a knowledge-based economy". In: OECD. The knowledge-based economy. Paris, 1998.

DUNNING, J. "The advent of alliance capitalism". DUNNING, J. e HAMDANI, $\mathrm{K}$. (eds.). The new globalism and developing countries, unite nations. Genebra, University Press, 1997.

EDQUIST, C. Systems of innovation technologies, institutions and organizations. Londres, Ed. Pinter, 1997.

FRANÇOIS, J.P. e FAVRE, F.L. "Innovation technologique progresse dans l'industrie". Statiques industrielles. Paris, Sessi, Ministère de l'Industrie, n.89, 2000.

FREEMAN, C. "Innovations systems: city-state, national, continental and subnational". Nota Técnica, 02/98. In: Ministério da Ciência e Tecnologia. Globalização e inovação localizada - Experiências de sistemas locais no Mercosul. Brasília, Instituto Brasileiro de Informação em Ciência e Tecnologia, 1998.

FORAY, D. e LUNDVALL, B.A. "The knowledge-based economy: from the economics of knowledge to the learning economy". In: OECD. The knowledge-based economy. Paris, 1996.

GEREFFI, G. e KORZENIEWICZ, M. Commodity chains and global capistalism. Wesport, Connecticut, Londres, Praeger, 1995.

GUILHON, B.; HUARD, P.; ORILLARD, M. e ZIMMERMANN, J.B. Économie de la connaissance et organisations: entreprises, territoires, reseaux. $\mathrm{Pa}-$ ris, Editions L'Harmattan, 1997.

HUMPHREY, J. e SCHMITZ, H. "The triple C approach to local industrial policy". World Development, v.24, n.12, 1996.
JOHNSON, B. e LUNDVALL, B.A. "Promoting innovation systems as a response to the globalising learning economy". International Seminar on Local Productive Clusters and Innovation Systems and New Industrial and Technological Policies. Universidade do Rio de Janeiro, set. 2000.

KLINE, S.J. e ROSEMBERG, N. "An overview of innovation”. In: LANDAU, R. e ROSEMBERG, N. (eds.). The positive sum strategy. Harnessing technology for economic growth. Washington, National Academy Press, 1986.

LASTRES, H. e CASSIOLATO, J.E. "Glória 2000 Manifesto: first draft based on the main conclusions". International Seminar on Local Productive Clusters and Innovation Systems and New Industrial and Technological Policies. Universidade do Rio de Janeiro, set. 2000.

LEYDESDORFF, L. e ETZKOWITZ, H. "The triple hélix as a model for innovation studies". Science and Public Policy. Inglaterra, v.25, n.3, 1998, p.195-203.

LICHT, G.; SCHNELL, W. e STAHL, H. Results of German innovation survey. Paris, OECD, 1995.

LÓPES, A. e LUGONES, G. "Los sistemas locales en el escenario de la globalización". Nota Técnica 15/98. In: Ministério da Ciência e Tecnologia. Op. cit., 1998.

LUNDVALL, B.A. (ed.) National systems of innovation: towards a theory of innovation and interactive learning. Londres, Printer, 1992.

MEISS, L. de. e LETA, J. O perfil da ciência brasileira. Rio de Janeiro, Ed. UFRJ, 1996.

MINISTÉRIO DA CIÊNCIA E TECNOLOGIA. Relatório dos resultados da Lei $n^{o}$ 8.249/91. Brasília, Setor de Tecnologias da Informação/Secretaria de Política de Informática e Automação - MCT, dez. 1998.

Relatório Anual de Avaliação da Utilização dos Incentivos Fiscais da Lei $n^{o}$ 8.661/93. Brasília, dez. 1999.

MONTOYMA, S. (org.). Fapesp: uma história de política científica e tecnológica. São Paulo, Fapesp, 1999.

NELSON, R. (ed.). National innovation systems: a comparative analysis. Nova York, Oxford University, 1993.

OECD. Transitions to learning economies and societies. Paris, $1996 \mathrm{a}$.

$$
\text { The knowledge-based economy. Paris, 1996b. }
$$

QUADROS CARVALHO, R. Programmable automation and employment in brazilian industry. Thesis submitter for the degree of DPhil - development studies. University of Sussex, 1993.

QUADROS, R. et alii. "Padrões de inovação tecnológica na indústria paulista: comparação com os países industrializados”. São Paulo em Perspectiva. São Paulo, Fundação Seade, v.13, n.1-2, 1999.

SALES-FILHO, S. (coord.). Ciência, tecnologia e inovação: a reorganização da pesquisa pública no Brasil. Ed. Komedi/Capes, 2000.

SANZ-MENÉDEZ, L. e GARCIA, C.E. Interfirm collaboration in Spain. Paris, OECD, abr. 1998.

SOUZA, M.C. e GARCIA, R. "Sistemas locais de inovação em São Paulo". In: Ministério da Ciência e Tecnologia. Op. cit., 1998.

STORPER, M. "Instituions of the knowledge-based economy". In: The knowledgebased economy. Paris, OECD, 1996.

USP. A presença da universidade pública. São Paulo, jan. 2000.

VILLASCHI, A.F. The brazilian national system of innovation: opportunities and constraints for transforming technological dependency. D. Phil Thesis, University of London, 1993.

VIOTTI, E.B. Passive and active national system of innovation: opportunities and constraints for transforming technological dependency. D. Phil Thesis, University of London, 1997. 